\title{
Narrativa fantástica e identidade brasileira na minissérie A cura ${ }^{1}$
}

\author{
Maria Cristina Palma Mungioli ${ }^{2}$ \\ Ligia Maria Prezia Lemos $^{3}$ \\ Issaaf Karhawi ${ }^{4}$
}

1 Trata-se de uma versão modificada e atualizada de trabalho apresentado no GP Ficção Seriada do XXXIV Congresso Brasileiro de Ciências da Comunicação, 2011.

2 Professora doutora da Escola de Comunicações e Artes da USP. Pesquisadora do Centro de Estudos de Telenovela da ECA-USP e do Obitel - Observatório Ibero-Americano da Ficção Televisiva. Coordenadora do GP Ficção Seriada da Intercom. crismungioli@usp.br.

3 Doutoranda em ciências da comunicação pela ECA-USP, bolsista do CNPq. Mestre em ciências da comunicação e especialista em gestão da comunicação pela ECA-USP. Pesquisadora do Centro de Estudos de Telenovela da ECA-USP e do Obitel - Observatório Ibero-Americano da Fiç̧ão Televisiva. ligia.lemos@usp.br.

4 Mestranda em ciências da comunicação pela ECA-USP. Pesquisadora do Centro de Estudos de Telenovela da ECA-USP e do Obitel - Observatório Ibero-Americano da Fiç̧ão Televisiva. issaaf@usp.br. 


\section{Resumo}

Este artigo analisa elementos da minissérie A cura (Globo, 2010) inserindo-os no quadro das narrativas fantásticas produzidas pela televisão brasileira na primeira década do século XXI. Presente na ficção televisiva brasileira, sobretudo a partir de meados da década de 1970, a narrativa fantástica (TODOROV, 2008) teve papel preponderante na constituição de um estilo de narrar e de um acabamento estético genuinamente brasileiros na televisão (BORELLI, 2001).

\section{Palavras-chave}

Narrativa fantástica, narrativa televisiva, minissérie brasileira.

\section{Abstract}

This article aims to analyze the miniseries $A$ Cura (Globo, 2010) including it into a scenario of fantastic narratives produced by Brazilian television in the first decade of the XXI century. Present in Brazilian television fiction since the 1970s, the fantastic narrative (TODOROV, 2008) has a remarkable role in the development of a narrative style and a genuinely Brazilian aesthetics (BORELLI, 2001).

\section{Keywords}

Fantastic narrative, television fiction, Brazilian miniseries. 
A minissérie $A$ Cura $^{5}$ apresentou aspectos de inovação em termos de construção narrativa - sobretudo no que se refere ao tratamento da temporalidade - e pela retomada, em termos de abordagem temática e gênero, do realismo fantástico que tanto marcou e marca a produção artística brasileira. A literatura nacional conta com inúmeros escritores que dominaram a arte de criar histórias em que o imponderável e o fantástico tecem as relações entre personagens e seus mundos, construindo, com base nesses mundos ficcionais, possibilidades diferentes, contraditórias e, às vezes, imponderáveis de dar sentido - até mesmo pelo estranhamento - à realidade, ou às realidades que permeiam nosso cotidiano. Entre esses escritores, apenas para citar alguns, encontramse Machado de Assis, Lima Barreto, Mário de Andrade, Guimarães Rosa, Jorge Amado, Érico Veríssimo, Lígia Fagundes Telles. Todos lançaram mão do realismo fantástico para tratar de assuntos muito próximos de nossa realidade, de nossa cultura, pois como lembra J. Merquior "(...) a concentração no imaginário é uma estratégia realista, muito mais do que uma volta anacrônica ao abstracionismo ou ao decorativismo esteticistas" (MERQUIOR, 1979, p. 397).

Muito presente na ficção televisiva brasileira, sobretudo a partir de meados da década de 1970, a narrativa fantástica (TODOROV, 2008), ou de apelo temático ao sobrenatural, teve papel preponderante na constituição de um estilo de narrar e de um acabamento estético genuinamente nacional na televisão. O realismo fantástico se apresenta na década de 1970, sobretudo nas telenovelas da Globo, mas também nas telenovelas da TV Tupi, como um importante recurso narrativo para a consolidação do gênero telenovela brasileira. A partir da década de 1990, o fantástico também pode ser notado nas minisséries da Globo ${ }^{6}$, gênero que se inicia em 1982, com a produção de Lampião e Maria Bonita (de autoria Aguinaldo Silva e Doc Comparato). Dois autores da ficção

5 Escrita por João Emanuel Carneiro e Marcos Bernstein, levada ao ar de 10/08/2010 a 12/10/2010, 9 capítulos, semanais. Direção de Ricardo Waddington.

6 O presente artigo se detém na discussão de telenovelas e minisséries brasileiras veiculadas pela Globo em razão de esta ser a emissora que mantém regularidade produção ao longo de décadas e, por isso, propiciar o enfoque diacrônico a que nos propomos. 
televisiva se tornaram responsáveis, na Globo, por tramas tecidas com base no universo do realismo fantástico: Dias Gomes e Janete Clair, porém autores como Ivani Ribeiro, Aguinaldo Silva, Ricardo Linhares, Luiz Fernando Carvalho entram no rol dos contadores de histórias fantásticas na teledramaturgia brasileira.

Levando em conta esse contexto, neste artigo procuramos analisar elementos da minissérie $A$ cura (Globo, 2010) inserindo-os no quadro das narrativas fantásticas produzidas pela televisão brasileira ao mesmo tempo em que procuramos traçar um quadro do gênero narrativa fantástica na teledramaturgia nacional. A narrativa de $A$ cura se constrói envolvendo dois eixos temporais, o passado - sob a perspectiva da memória étnica (LE GOFF, 2003) - e o presente, que se entrecruzam construindo um sentido identitário de Brasil marcado não por discursos antagônicos, mas por discursos que se completam e se interrogam dialogicamente (BAKHTIN, 2002, 2003).

\section{Aspectos da narrativa fantástica e do realismo fantástico}

E. Forster afirma que a literatura fantástica exige do leitor uma "adaptação adicional devido à singularidade de seu método ou tema" (1998, p. 102), pois nem todos querem ou estão preparados a adentrar o mundo da fantasia ou mesmo o desejam. Essa adaptação requer a aceitação de um mundo ficcional no qual o princípio fundador da ficção, a verossimilhança, ganha modulações que forjam o mundo ficcional e o inserem em uma multidimensionalidade espacial ou temporal. Nela, as leis da natureza tais como as conhecemos são subvertidas. Essa subversão coloca em xeque nosso conhecimento de mundo, ou seja, nossa enciclopédia, da qual fazem parte tanto os mundos reais quanto os mundos possíveis (ECO, 1997). No entanto, a narrativa fantástica, ao expandir o princípio da verossimilhança aos limites do insólito e da dúvida, coloca em marcha um processo em que o ficcional e o real se fundem e, muitas vezes, desnorteia o leitor/telespectador, levando-o a acreditar que se trata de um engodo. No entanto, muitas vezes nos damos conta desse engodo, mas a 
construção narrativa ancorada nos pilares dos mitos, das crenças religiosas, do saber popular, enfim, da memória étnica (LE GOFF, 2003) coloca em marcha uma temática que nos circunscreve cada vez mais nos limites do mundo fantástico.

Assim, preso ao princípio da versossimilhança e, em certa medida, à realidade, coloca-se diante de nós um mundo ficcional possível, aceitável devido à construção narrativa. Mundo que se molda ficcionalmente à perfeição "por meio da insistência em detalhes inverificáveis e intrusões introspectivas, pois nenhum relato histórico pode suportar tais efeitos de realidade" (ECO, 1997, p. 128). Detalhes que nos intrigam, pois jogam com os duplos, com a ambiguidade, com as modulações de um mundo ficcional que se cola ao "mundo real" nos mínimos detalhes. Forster argumenta que, nas narrativas fantásticas,

\footnotetext{
o material da vida diária será repuxado e esticado em várias direções, a terra sofrerá pequenas deformações malévolas ou melancólicas (...). O poder da fantasia penetra em cada canto do universo, mas não nas forças que o governam (...) e os romances desse tipo possuem um ar de improvisados, sendo esse o segredo de sua força e encanto (FORSTER, 1998, p. 103).
}

O inusitado, o inédito, o inesperado está no cotidiano, nos afazeres domésticos, na lida do trabalho, enfim, nas artes de fazer e nas artes de dizer (DE CERTEAU, 2007), e é nesse terreno tão prosaico quanto conhecido que o fantástico surge. Como fazer frente à dúvida, à ambiguidade, que se instala em objetos e pessoas (personagens) tão próximos de nós?

Segundo T. Todorov $(2003,2008)$, para que a narrativa fantástica se concretize e apresente ao leitor - em nosso caso, ao telespectador estranhezas em relação ao mundo familiar, é necessária a hesitação. O fantástico está instaurado na incerteza, entre o que é real e o que é incerto. Quando, ao final da narrativa, o leitor se diz "quase cheguei a acreditar", está aí a melhor sentença para resumir o fantástico, "a fé absoluta, como a incredulidade total, nos levam para fora do fantástico; é a hesitação que Ihe dá vida" (TODOROV, 2003, p. 150). 
A hesitação vital ao fantástico também é originária de uma construção que não cabe apenas ao autor da trama, mas à maneira com que o telespectador a lê. O que T. Todorov destaca na narrativa fantástica, U. Eco (1997, p. 4) sinaliza para todas as ficções: "(...) numa história sempre há um leitor, e esse leitor é um ingrediente fundamental não só do processo de contar uma história, como também da própria história".

No fantástico, a construção narrativa lança mão de estratégias discursivas de modo a fazer com que o leitor se identifique com a personagem, sinta seus medos, tenha o coração palpitante diante do insólito que presencia. A hesitação que tece a narrativa deve ser comum a ambos. É por isso que, ao adentrar uma narrativa fantástica, o leitor não deve estar avisado da verdade: "o fantástico implica (...) uma integração do leitor no mundo das personagens" (TODOROV, 2003, p. 150-151).

É sobre esses elementos que a narrativa fantástica se consolida, o leitor crê no mundo das personagens e hesita com elas entre as explicações naturais e sobrenaturais dos fenômenos. Esse envolvimento, inscrito no modo de se construir e de se ler a trama, segue um ritmo definido por T. Todorov pela negação de uma afiliação literária convencional: "ele não deve ser nem poético nem alegórico" (2003, p. 151). Formular interpretações alegóricas para os eventos é acabar com o fantástico. A volta do leitor para o seu mundo "real" é um risco, uma ameaça, para esse gênero. Em seu papel, quase mimético ao da personagem, o leitor deve apenas viver os fenômenos, imaginá-los: aceitar o acordo ficcional de "suspensão da descrença" (ECO, 1997) e levar a ficção a sério.

Como toda classificação genérica, a narrativa fantástica não é um gênero preciso, ela transita entre dois mundos vizinhos, o do estranho e o do maravilhoso. No gênero do estranho, as leis da realidade permanecem intactas e explicam o fenômeno incomum, já no maravilhoso, a explicação dos eventos ocorridos é creditada a novas leis da natureza (TODOROV, 2003) como um gato falar no caso das fábulas, por exemplo. A transição entre esses três gêneros eclode em cinco 
subgêneros, classificados de acordo com T. Todorov em: fantástico-estranho, estranho-puro, fantástico-puro, fantástico-maravilhoso e maravilhoso-puro. Essas subdivisões são postas ora entre o fantástico e o estranho ora entre o fantástico e o maravilhoso.

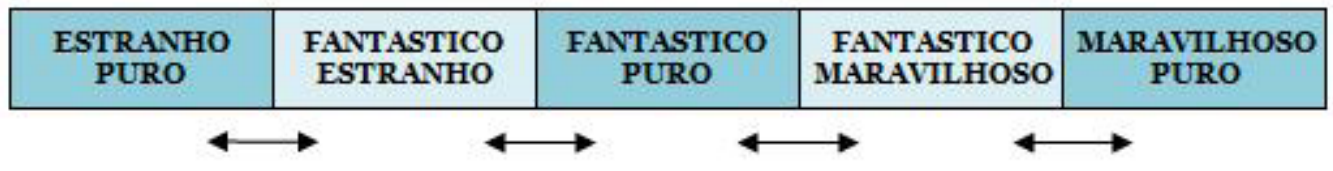

Figura 1: Gêneros e subgêneros da narrativa fantástica

No fantástico-estranho, os eventos "sobrenaturais" são, geralmente, ocasionados por acasos, sonhos, influência de drogas, ilusão dos sentidos ou pela loucura. Assim, neste subgênero, estão as narrativas em que os acontecimentos têm explicações reais. A hesitação desse tipo de narrativa está na dicotomia entre real-imaginário e real-ilusório.

O estranho-puro compreende eventos chocantes, inquietantes que podem ser explicados pela razão, mas não o são. Para T. Todorov (2003, 2008), o estranho-puro é um subgênero e, assim como o gênero fantástico, de identificação imprecisa. As narrativas assim classificadas abarcam coincidências e experiências dos limites humanos, como a crueldade extrema. Já o fantásticomaravilhoso é o subgênero mais próximo do fantástico-puro. Os eventos do fantástico-maravilhoso não podem ser explicados pela razão, a justificativa sugere a existência do sobrenatural.

O último subgênero transitório é o maravilhoso-puro que, assim como o estranho-puro, não possui limites claros, mas os eventos sobrenaturais e incomuns não causam reação alguma. Nesse subgênero, estão inseridos os contos de fadas e as histórias de ficção científica. Na linha mediana da transição dos subgêneros está o fantástico-puro.

As categorias propostas por T. Todorov nos ajudam a deslindar alguns aspectos referentes à tematização da narrativa fantástica. Porém, como todo 
discurso, o fantástico se alicerça sobre princípios referentes não apenas à tematização, mas também ao processo enunciativo. Nas palavras de T. Todorov, "o gênero fantástico é pois definido essencialmente por categorias que dizem respeito às visões da narrativa; e, em parte, por seus temas" (2008, p. 152).

\section{Narrativas de realismo fantástico na televisão}

A televisão, devido a suas características peculiares, usa e abusa do caráter fragmentado e provisório contido na atualidade do cotidiano, acompanha essa fragmentação e a oferece para degustação a seus telespectadores em doses diárias e em horário certo por meio de formatos seriados.

Essa cotidianidade marca de maneira indelével a teledramaturgia brasileira, sobretudo a telenovela. Segundo M. Motter (2000-2001), a telenovela brasileira se constituiu ao longo do tempo por meio de duas características: o fio melodramático e a cotidianidade - ancorada numa rigorosa observação do princípio da verossimilhança. Além disso, a linguagem da televisão baseada na iconicidade da imagem proporciona uma aproximação direta com o real.

Essa proximidade com a realidade não implica um distanciamento em relação ao fantástico, ao contrário, como vimos, a proximidade com o cotidiano, com a realidade, possibilita e amplifica a criação de mundos ficcionais inscritos no insólito e no inexplicável.

\section{Narrativas fantásticas e realismo fantástico na ficção televisiva}

Sem a pretensão de apresentar um quadro definitivo sobre as narrativas de realismo fantástico nas telenovelas e minisséries produzidas pela Globo, apresentamos a seguir dados que exemplificam a importância desse gênero na ficção televisiva nacional. No gráfico abaixo, observa-se, desde a década

7 Os dados referentes ao emprego de temática fantástica ou de elementos narrativos que fazem apelo ao sobrenatural foram retirados de fontes diversas (GUIA ILUSTRADO TV GLOBO: novelas e Minissérie. Rio de Janeiro: Zahar, 2010; FERNANDES, I. Telenovela Brasileira: memória. São Paulo: Brasiliense, 1987; site Memória Globo, http://memoriaglobo. 
de 1970, uma constância em termos de presença de narrativas fantásticas no cenário de produção de telenovelas. Verifica-se ainda que, a partir de meados da década de 1990, ocorre maior produção do gênero com três produções entre 2000-2001.

No que se refere às minisséries, observa-se igual movimento de aumento da produção no mesmo período. Especulamos que a relevância da narrativa fantástica ou de apelo ao sobrenatural possa estar ligada ao início do novo milênio e aos habituais questionamentos sobre o futuro da humanidade que ocorrem nesse período. Aliás, a telenovela O fim do mundo, de Dias Gomes, exibida em 1996, abordou parte dos medos e angústias do ser humano na virada do milênio frente às forças destrutivas da natureza, do cosmos. No entanto, em relação às minisséries, observa-se ainda um aumento de produções do gênero fantástico no ano de 2005, com duas produções de Luiz Fernando Carvalho (Hoje é dia de Maria e Hoje é dia de Maria - Segunda Jornada) que tratam da cultura brasileira retratada nos contos populares.

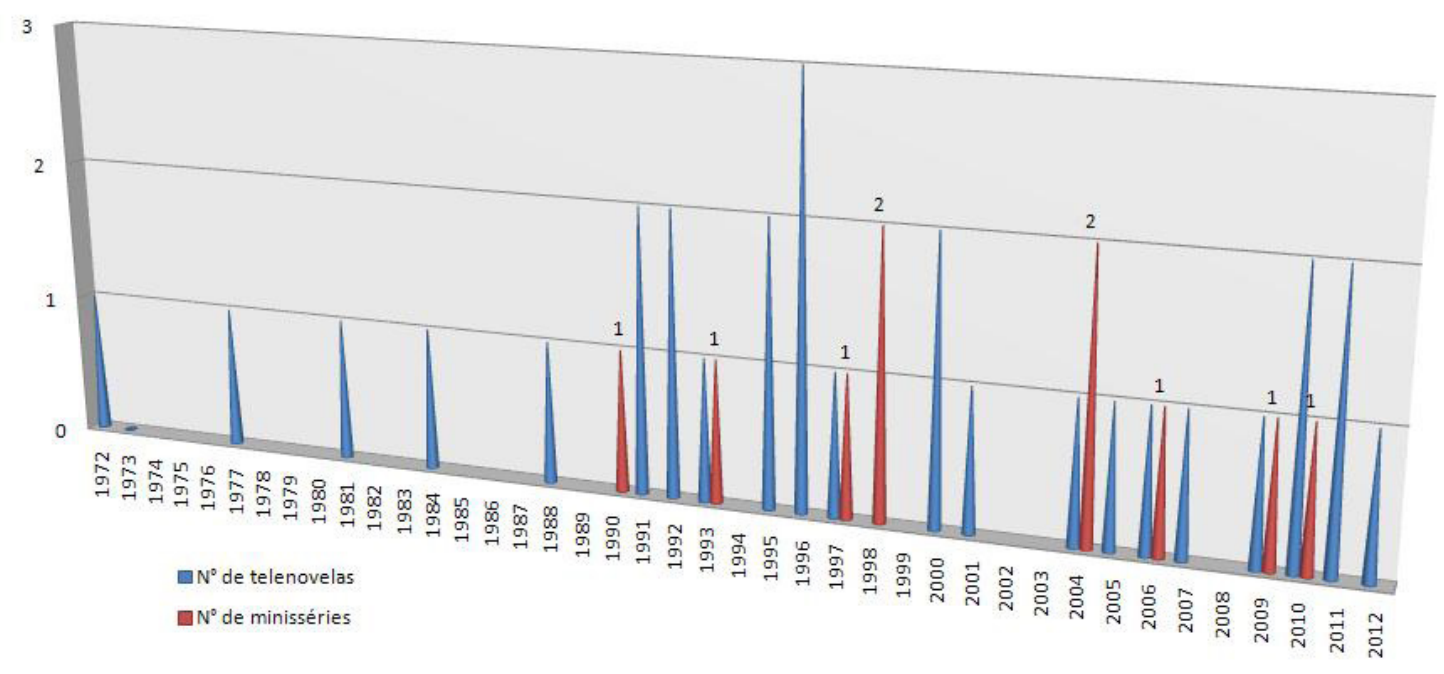

Gráfico 1: Número de Ficções Televisivas envolvendo Narrativas Fantásticas (1971-2012) 
As obras ficcionais, em geral, e de televisão, em particular, podem ser classificadas em mais de um gênero dependendo dos critérios empregados para sua categorização. Quando se trata do fantástico essa característica se expande ainda mais, pois seu sentido atravessa o espaço da ilusão - da personagem ou do leitor ou, ainda, de ambos - transita pelo limiar, pela incerteza, pelo inexplicável que se instala na chamada vida real do personagem criando um clima, uma atmosfera, de dúvida. Surge daí uma hesitação dos sentidos, uma insegurança frente ao que é aparentemente sobrenatural. Enquanto dura essa incerteza, essa hesitação, estamos no ambiente do fantástico, de seus climas, impressões e intensidades emocionais.

No levantamento das telenovelas e minisséries da Rede Globo do período de 1971 a 2012, apresentado abaixo, observa-se o trânsito impreciso e intermitente pelos subgêneros. Assim, nas telenovelas, verifica-se a recorrência de temas ligados à reencarnação, ao espiritismo, ao insólito, ao fantástico e à paranormalidade. Também de maneira prevalente surge a sátira, gênero que se caracteriza por um tratamento narrativo-discursivo que exige distanciamento em relação ao "real e ao verdadeiro". 


\begin{tabular}{|c|c|c|c|}
\hline Titulo & AUTOR & EXIBIÇÄO & $\begin{array}{l}\text { TEMAS / ELEMIENTOS } \\
\text { REALISMO FANTASTICO }\end{array}$ \\
\hline $\begin{array}{l}\text { 1. O homem que } \\
\text { deve morrer }\end{array}$ & Janete Clair & jun 71 a abr 72 & sonhos / premoniç̧oses / mistérios / santidade \\
\hline 2. O bofe & $\begin{array}{l}\text { Bráulio Pedroso e } \\
\text { Lauro Céaar Muniz }\end{array}$ & jul 72 ajan 73 & $\begin{array}{l}\text { tipos e situaçóes absurdas, caricatas e } \\
\text { sumrealistas / ex: personagem que 'morre de } \\
\text { rir' }\end{array}$ \\
\hline 3. O Bem-amado & Dias Gomes & jan a out 73 & aśtiras / o insólito e o fantástico \\
\hline 4. Saramandaia & Dias Gomes & mai a dez 76 & $\begin{array}{l}\text { aátiras / o insólito e o fantástico / } \\
\text { personagens exóticos / subversaào das leis } \\
\text { naturais }\end{array}$ \\
\hline 5. Sétimo sentido & Janste Clair & mar a out 82 & $\begin{array}{l}\text { paranormalidade / parapsicologia / dupla } \\
\text { personalidade / possasaào / reencamaçăo / } \\
\text { carma }\end{array}$ \\
\hline 6. Roque Santeiro & Disa Gomes & jun 85 a fev 86 & $\begin{array}{l}\text { sátiras / o insólito e o fantástico / } \\
\text { personagens de tipos folclóricos e absurdos / } \\
\text { temsa sumrealistas / mitificaçajo / milagres }\end{array}$ \\
\hline 7. Tieta & $\begin{array}{l}\text { Aguinaldo Silva } \\
\text { AnaMaria } \\
\text { Moretzaohne } \\
\text { Ricardo Linharea }\end{array}$ & ago 89 a mar 90 & $\begin{array}{l}\text { aátiras e metáforas / o insólito e o fantáatico } \\
\text { / vingança }\end{array}$ \\
\hline 8. Vamp & Antônio Calmon & jul 91 a fev 92 & $\begin{array}{l}\text { vampiros / comércio de almas / } \\
\text { rencamaçăo / maldiçòes }\end{array}$ \\
\hline $\begin{array}{l}\text { 9. Pedra sobre } \\
\text { pedra }\end{array}$ & $\begin{array}{l}\text { Aguinaldo Silva, } \\
\text { Ana Maria } \\
\text { Moretzaohn e } \\
\text { Ricardo Linhares }\end{array}$ & jam a ago 92 & $\begin{array}{l}\text { sátiras / o inálitito e o fantástico/ } \\
\text { predestinaçâo e fatalidade / objetos mágicos } \\
\text { / seres com poderes mágicos }\end{array}$ \\
\hline 10. Olho no olho & Antônio Calmon & set 93 a abr 94 & $\begin{array}{l}\text { paranomalidade / poderes sobrenaturais / } \\
\text { forças malignas }\end{array}$ \\
\hline 11. Fera ferida & $\begin{array}{l}\text { Aguinaldo Silva, } \\
\text { Ana Maria } \\
\text { Moretzaohne } \\
\text { Ricardo Linharea }\end{array}$ & nov 93 a jul 94 & $\begin{array}{l}\text { confusao de identidades, imortalidade, } \\
\text { poderes sobrenaturais, conhecimentos } \\
\text { esotericos. }\end{array}$ \\
\hline 12. Aviagem & Ivani Ribeiro & abr a out 94 & $\begin{array}{l}\text { amizade imaginária/ influéncia malévola/ } \\
\text { predestinaçâo/reencamaçâo }\end{array}$ \\
\hline 13. O fim do mumdo & Diss Gomes & mai ajun 96 & $\begin{array}{l}\text { átiras / o insólito e o fantástico / } \\
\text { paranomalidade / fim do mundo }\end{array}$ \\
\hline 14. Anjo de mim & Walther Negrào & set 96 a mar 97 & $\begin{array}{l}\text { regressôes a vidas passadas / visöes / sonhos } \\
\text { / reencamaçäo }\end{array}$ \\
\hline $\begin{array}{l}\text { 15. } \mathrm{O} \text { amor está no } \\
\text { ar }\end{array}$ & Alcides Nogueira & mar a set 97 & vida extraterrestre / abduçào \\
\hline 16. Aindomada & $\begin{array}{l}\text { Aguinaldo Silvae } \\
\text { Ricardo Linhares }\end{array}$ & fev a out 97 & $\begin{array}{l}\text { sátiras / o insólito e o fantástico / dons } \\
\text { sobrenaturais / figuras misteriosas }\end{array}$ \\
\hline 17. Zazá & Lauro Céaar Muniz & mai 97 ajan 98 & anjos / anjos da guarda / mistérios \\
\hline $\begin{array}{l}\text { 18. Meu bem- } \\
\text { querer }\end{array}$ & Ricardo Linhares & ago 98 a mar 99 & sátiras / o insólito e o fantástico / mistérios \\
\hline $\begin{array}{l}\text { 19. Um anjo cain do } \\
\text { céu }\end{array}$ & Antônio Calmon & jan a ago 2001 & $\begin{array}{l}\text { anjos / missāo / poderes mágicos e } \\
\text { imortalidade / troca de identidade }\end{array}$ \\
\hline $\begin{array}{l}\text { 20. Porto dos } \\
\text { milagres }\end{array}$ & $\begin{array}{l}\text { Aguinaldo Silvae } \\
\text { Ricardo Linhares }\end{array}$ & fev a set 2001 & sátiras / o insólito e o fantástico / \\
\hline 21. Estrela-guia & $\begin{array}{l}\text { Ana Maria } \\
\text { Moretzaohn }\end{array}$ & mar ajun 2001 & $\begin{array}{l}\text { crenças cósmicas / comunidade hippie / } \\
\text { dom da cura }\end{array}$ \\
\hline $\begin{array}{l}22 . \text { O beijo do } \\
\text { vampiro }\end{array}$ & Antônio Calmon & $\begin{array}{l}\text { ago } 2002 \text { a mai } \\
2003\end{array}$ & $\begin{array}{l}\text { vampiros / reencamação / maldiçōes / } \\
\text { obsessăo }\end{array}$ \\
\hline 23. Alma Gêmea & Walcyr Carrasco & $\begin{array}{l}\text { jun } 2005 \text { a mar } \\
2006\end{array}$ & predestinaçâo/ reencamaçâo / alma gêmes \\
\hline 24. O profeta & $\begin{array}{l}\text { Ivani Ribeiro, } \\
\text { Thelma Guedes e } \\
\text { Duca Rachid }\end{array}$ & $\begin{array}{l}\text { out } 2006 \text { amai } \\
2007\end{array}$ & clarividência/ dom da cura/charlatanismo \\
\hline 25. Etema Magia & Elizabeth Jhin & mai anov 2007 & $\begin{array}{l}\text { bruxaria / lendas / vidência / viad̂es } \\
\text { espiritusis / sonho e fantasia }\end{array}$ \\
\hline $\begin{array}{l}\text { 26. Negócio da } \\
\text { China }\end{array}$ & Miguel Falabella & $\begin{array}{l}\text { out } 2008 \text { a mar } \\
2009\end{array}$ & $\begin{array}{l}\text { Mediunidade / obsessaso/ desaparecimento / } \\
\text { loucura }\end{array}$ \\
\hline $\begin{array}{l}\text { 27. Escrito nas } \\
\text { estrelas }\end{array}$ & Elizabeth Jhin & abr a set 2010 & $\begin{array}{l}\text { predestinaçào / reencamaçào/ vida após a } \\
\text { morte/ clarividência }\end{array}$ \\
\hline 28. Araguaia & Walther Negrăo & $\begin{array}{l}\text { sat } 2010 \text { a abr } \\
2011\end{array}$ & $\begin{array}{l}\text { maldição hereditária curas / protş̧âo } \\
\text { mágica }\end{array}$ \\
\hline 29. OAstro & $\begin{array}{l}\text { Alcides Nogueira e } \\
\text { Geraldo Cameiro }\end{array}$ & jul a out 2011 & $\begin{array}{l}\text { premoniçôes/paranomalidade magia/ } \\
\text { poderes aobrenaturais/clarividância }\end{array}$ \\
\hline $\begin{array}{l}\text { 30. Amor eterno } \\
\text { amor }\end{array}$ & Elizabeth Jhin & mar a set 2012 & $\begin{array}{l}\text { Vidas passadas / espíritos / regressâo / alma } \\
\text { gêmea }\end{array}$ \\
\hline
\end{tabular}

Quadro 1: Realismo Fantástico - Telenovelas ${ }^{8}$ 
De acordo com C. Mungioli (2010), no contexto televisual brasileiro, as minisséries se configuram como produtos diferenciados tanto em termos de tratamento temático, estético e discursivo, quanto em termos de orçamentos de produção. De maneira geral, pode-se dizer que os bons resultados colhidos por essas produções deve-se, em grande parte, a uma proposta que busca aliar a abordagem de temas e/ou de obras literárias de reconhecido valor social e estético ao trabalho de autores experientes. Seus roteiros produzidos em grande cumplicidade com diretores talentosos e elencos exaustivamente preparados com vistas a essas produções têm conseguido desenvolver obras de qualidade. Dessa forma, a apresentação destas minisséries, que contêm em sua trama elementos do realismo fantástico, ou mesmo que têm sua estrutura dramática alicerçada sobre o próprio questionamento em relação ao real e ao insólito, é reveladora de características importantes da cultura brasileira. Em relação ao formato minissérie, temos a fábula, o mistério, a maldição e a própria cultura popular gerando o insólito e questionando o "real". 


\begin{tabular}{|c|c|c|c|}
\hline TÍTULO & AUTOR & EXIBIĈ̣̃O & $\begin{array}{l}\text { TEMAS / ELEMENTOS } \\
\text { REALISMO FANTÁSTICO }\end{array}$ \\
\hline $\begin{array}{l}\text { 1. O sorriso do } \\
\text { lagarto }\end{array}$ & $\begin{array}{l}\text { Walther Negrão e } \\
\text { Geraldo Cameiro }\end{array}$ & jun a ago 91 & $\begin{array}{l}\text { experiências genéticas / mudança de } \\
\text { personalidade / seres híbridos }\end{array}$ \\
\hline $\begin{array}{l}\text { 2.Incidente em } \\
\text { Antares }\end{array}$ & $\begin{array}{l}\text { Nelson Nadottie } \\
\text { Charles Peixoto }\end{array}$ & nove dez 94 & $\begin{array}{l}\text { sátiras / o insólito e o fantástico / mortos } \\
\text { que retomam ao mundo dos vivos }\end{array}$ \\
\hline $\begin{array}{l}\text { 3. Dona Flor e } \\
\text { seus dois maridos }\end{array}$ & Dias Gomes & mara mai 98 & $\begin{array}{l}\text { o insólito e o fantástico / fantasma/ } \\
\text { fómulas mágicas }\end{array}$ \\
\hline $\begin{array}{l}\text { 4.O Auto da } \\
\text { Compadecida }\end{array}$ & $\begin{array}{l}\text { Guel Arraes, } \\
\text { Adriana Falcão e } \\
\text { João Falcão }\end{array}$ & jan 99 & $\begin{array}{l}\text { sátiras/o insólito e o fantástico/juízo } \\
\text { final/Deus e diabo/ destino }\end{array}$ \\
\hline 5. Luna Caliente & $\begin{array}{l}\text { Jorge Furtado, } \\
\text { Giba Assis Brasil } \\
\text { e Carlos Gerbase }\end{array}$ & $\operatorname{dez} 99$ & $\begin{array}{l}\text { 'tragédia de erros' / mistérios / } \\
\text { ressurreição / paranóia, o insólito }\end{array}$ \\
\hline $\begin{array}{l}\text { 6. Hoje é dia de } \\
\text { Maria }\end{array}$ & $\begin{array}{l}\text { Luiz Femando } \\
\text { Carvalho e Luis } \\
\text { Alberto de Abreu }\end{array}$ & jan 2005 & $\begin{array}{l}\text { universo da cultura popular / fábula/ } \\
\text { ressurreição / personagens fantásticos/ } \\
\text { maldição }\end{array}$ \\
\hline $\begin{array}{l}\text { 7. Hoje é dia de } \\
\text { Maria-Segunda } \\
\text { jornada }\end{array}$ & $\begin{array}{l}\text { Luiz Femando } \\
\text { Carvalho e Luis } \\
\text { Alberto de Abreu }\end{array}$ & out 2005 & $\begin{array}{l}\text { universo da cultura popular/fábula/ } \\
\text { personagens fantásticos }\end{array}$ \\
\hline $\begin{array}{l}\text { 8. A pedra do } \\
\text { reino }\end{array}$ & $\begin{array}{l}\text { Luiz Femando } \\
\text { Carvalho, Luís } \\
\text { Alberto de Abreu } \\
\text { e Bráulio Tavares }\end{array}$ & jun 2007 & $\begin{array}{l}\text { universo da cultura popular/fábula/ } \\
\text { memória ancestral/jogo de } \\
\text { temporalidades }\end{array}$ \\
\hline 9.A Cura & $\begin{array}{l}\text { João Emanuel } \\
\text { Cameiro e } \\
\text { Marcos Bemstein }\end{array}$ & ago a out 2010 & $\begin{array}{l}\text { predestinação/dom da cura/ } \\
\text { curandeirismo / mistérios / maldição } \\
\text { hereditária / maldições }\end{array}$ \\
\hline
\end{tabular}

Fontes: Guia Ilustrado TV Globo - Novelas e Minisséries; Telenovela Brasileira - Memória; e Memória Globo

Quadro 2: Realismo Fantástico - Minisséries

Entre os autores que mais empregaram o gênero fantástico destacamos, nas telenovelas, Dias Gomes, Aguinaldo Silva, Ricardo Linhares, Ana Maria Moretzsohn e Antônio Calmon e, nas minisséries, Luiz Fernando Carvalho e Luís Alberto de Abreu.

\section{A minissérie A Cura}

A Cura é uma minissérie em formato de thriller, com nove episódios, ambientada em Diamantina, Minas Gerais. A história tem como eixos temporais condutores da trama dois personagens, Silvério (Carmo Dalla Vecchia) e Dimas (Selton Mello). As histórias de ambos confluem para o sobrenatural, para o fantástico e à medida que a trama avança, compreende-se a relação genética entre as personagens, seus dramas, suas maldições. Dimas, um jovem cirurgião, 
volta à cidade de Diamantina vinte anos depois de tê-la deixado em razão da acusação de matar um amigo de infância. Logo depois de sua chegada, passa a trabalhar no hospital da cidade, onde é proibido de realizar cirurgias devido ao crime que supostamente cometera no passado. Apesar da proibição, Dimas é praticamente impelido a isso por pessoas que o consideram como perpetuador da obra de Otto (Juca de Oliveira), médico que todos acreditam estar morto e que operava cirurgias espirituais milagrosas. Dimas descobre então que tem o dom da cura e passa a realizar clandestinamente, e quase contra a sua vontade, cirurgias "espirituais". Dimas não compreende o que se passa, não sabe se se trata de um dom ou de uma maldição, pois seus pacientes, depois de curados, morrem inexplicavelmente. Dimas hesita diante dos fatos e não compreende seus dons e mesmo seu passado, no qual se entrecruzam Otto (que Dimas descobre ser seu pai) e Silvério. Este último, um antepassado de Dimas, é um violento e cruel minerador de ouro no século XVIII que maltrata escravos e mata qualquer um que atravesse seu caminho e atrapalhe seus objetivos ambiciosos. Amaldiçoado por um pajé, Silvério sofre de uma dolorosa doença que o desfigura e para a qual busca a cura a qualquer preço. A história se passa numa atmosfera de mistérios e segredos, com idas e vindas entre as três temporalidades ligadas à trajetória de três personagens: Silvério, no século XVIII, Otto na década de 1980 e Dimas e Otto, na atualidade. A contraposição constante entre esses tempos e personagens propõe paradoxalmente a complementaridade e a dissonância entre suas visões de mundo e sugere um ajuste de contas entre personagens que compartilham, em diferentes épocas, um carma, um destino.

O diretor do hospital da cidade, Dr. Turíbio (Ary Fontoura), é pai da médica Rosângela (Andréia Horta) - amiga de infância e primeiro amor de Dimas -, que é noiva de Camilo (Caco Ciocler), também médico. Rosângela, ao se envolver amorosamente com Dimas, rompe o noivado com Camilo e torna-se a principal incentivadora para que Dimas faça uso de seus dons de cura. O envolvimento entre ambos ganha contornos de cumplicidade que os leva a situações de suspense e de perigo de vida. As curas de Dimas despertam o interesse de Otto, supostamente já falecido, considerado criminoso por uns e santo por outros. 
A série aborda o tema das vidas passadas, criando uma ambiência marcada pelo suspense e pela ambiguidade, tanto no presente, com o conflito de Dimas frente sua capacidade paranormal de curar com as mãos, quanto no passado, que envolve assassinatos e rituais que seus conterrâneos e familiares insistem em esquecer.

A análise da minissérie $A$ Cura de acordo com a estrutura narrativa fantástica proposta por T. Todorov (2003), possibilita enxergar a trama por aspectos diversos. O principal deles, peça fundamental na construção desse gênero é a hesitação, como coloca o autor. Podemos citar como exemplos do fantástico, os eventos apresentados logo no primeiro episódio, que permitem perceber a hesitação. Não é apenas o telespectador que não sabe se Dimas é ou não um assassino, a própria personagem tem dúvidas sobre isso. Instaurase aí a contradição entre o real-imaginário e o real-ilusório. A hesitação, o desconhecimento de si-mesmo de Dimas coloca em dúvida o telespectador. Como acreditar em Dimas se ele próprio não acredita? A ambiguidade, a falta de bases "concretas" para crer na inocência ou na culpa de Dimas, sinaliza a relação integrada entre o mundo da personagem e o do leitor apontada por $\mathrm{T}$. Todorov (2003). A primeira passagem da minissérie já "(...) obrig[a] o leitor a (...) hesitar entre uma explicação natural e uma explicação sobrenatural dos acontecimentos evocados" (TODOROV, 2003, p. 151).

Essa hesitação permanecerá ao longo da minissérie, pois ela é decorrente dos fatos narrados e, principalmente, do próprio questionamento que envolve Dimas não apenas em relação a seus poderes de cura, mas sobretudo em relação à filiação desses poderes: eles são decorrentes de Deus ou do Diabo (este último encarnado na figura de Otto, de quem Dimas é filho)? Por outro lado, a hesitação e o clima de thriller permanecem até o final da minissérie, que não apresenta um desfecho convencional para os conflitos. Dimas, acusado de tentar matar Rosângela, já encarcerado recebe a visita de Camilo que Ihe promete libertá-lo para então matarem Otto e para curar Rosângela, que está hospitalizada e se encontra inconsciente entre a vida e a morte. A minissérie termina quando a 
câmera se aproxima do rosto de Rosângela, simulando a aproximação de uma pessoa, e ela abre os olhos e deixa os telespectadores perplexos. Quem ela vê? Otto? Dimas? Devido a esse final polissêmico e inconclusivo, muitos acreditam que $A$ cura terá uma segunda temporada.

Assim, entre outros elementos narrativos da minissérie $A$ cura, merecem destaque o tratamento das temporalidades narrativas e o acabamento estético apurado. A narrativa é marcada por flashbacks, flashforwards e digressões que inter-relacionam as dimensões de tempo cronológico e tempo psicológico ao mesmo tempo em que demandam que o leitor faça uma articulação constante entre tempo da narrativa e tempo do discurso. Em relação ao tratamento estético, deve-se ressaltar a crueza das cenas que envolvem cirurgias e assassinatos conferindo à minissérie um realismo poucas vezes visto na TV brasileira. Em termos de narração/enunciação fílmica, deve-se ainda ressaltar a iluminação que permitiu a criação de ambientes sombrios que, aliados a espaços de porões labirínticos e prisões, sugerem a introspecção e os conflitos da alma e do espírito enraizados na luta ancestral entre o Bem e o Mal.

Em termos de formato e exibição, $A$ cura também foi precursora de um novo tipo de minissérie, com apresentação de um capítulo por semana ao invés de diariamente, como era o costume das minisséries brasileiras. Essa modificação na exibição demandou alterações temáticas e estruturais de roteiro e edição, pois foi necessário criar ganchos de maior intensidade dramática e procedimentos de edição para que o telespectador não apenas se recordasse da trama, mas também fosse motivado a acompanhá-la.

\section{As temporalidades e a construção do discurso sobre o povo brasileiro}

Como ponto de partida para a reflexão acerca da produção de sentido de identidade brasileira em $A$ cura, entende-se que o gênero teledramatúrgico se constitui como lugar de memória (MOTTER, 2000-2001). Assim, é espaço de construção de significados e, por conseguinte, uma das formas pelas quais se 
constitui(em) a(s) identidade(s) brasileira(s) que forja(m) os sentidos de uma nacionalidade (LOPES, 2004). Nacionalidade impregnada, de maneira indelével, pelas imagens de um Brasil visto, sentido e compreendido não apenas pelas imagens de TV, mas também por todo um universo discursivo em que se podem notar as lutas ideológicas, os interesses econômicos. Enfim, a luta pela hegemonia em que se destaca o poder das narrativas e do uso social que delas se faz.

O tratamento diferenciado do elemento narrativo temporal apresentase como uma das principais características da minissérie. Em televisão, em geral, e em ficção televisiva, em particular, o tratamento das temporalidades se apresenta de maneira complexa, uma vez que tanto a programação quanto a audiência são fragmentadas no tempo e no espaço. Isso implica que haja na construção do enredo uma atenção maior para com marcadores temporais cênicos e enunciativos.

A Cura apresenta o tratamento temporal de maneira complexa, pois se entrecruzam três temporalidades que colocam em jogo o passado histórico (a exploração do ouro em Minas Gerais, a fundação de Diamantina, o extermínio dos índios e a exploração dos mais fracos pelos poderosos senhores de terras) e, contrapondo-se a ele, o passado (atualizado) pela narrativa. No caso da minissérie, esse passado é confrontado também em termos de ligação genética e ética entre o poderoso e malvado Silvério e o jovem médico Dimas, entre visões de mundo que se contrapõem, que se alicerçam sobre pilares completamente diferentes e que evidenciam transformações sociais em termos de relação de poder.

Essa correlação de tempo-espaço evidencia as relações entre personagens e seu horizonte social (BAKHTIN, 2002), seu estatuto sócio-histórico, denotando cronotopos diferentes frente a modulações que se impõem por um mesmo questionamento ético. ${ }^{9}$ No caso de $A$ cura, pode-se dizer que essa relação é incorporada à ficção televisiva por meio dos discursos entre Silvério e os

9 Cronotopo é o conceito criado por Bakhtin (1993) para investigar a inter-relação tempo-espaço no romance. Para ele, as dimensões temporal e espacial se manifestam por meio da inter-relação entre forma e conteúdo. Inter-relação essa mediada pelo tempo-espaço (cronotopo) presente na sociedade e que é incorporada à literatura. 
índios. Discurso que se enuncia por meio de armas e estratégias do colonizador português sobre o colonizado, a quem resta sobreviver e lutar por meio de táticas construídas pelo saber ancestral ao qual o colonizador é incapaz de aceder (DE CERTEAU, 2007). Surge assim um cronotopo típico das relações colonizador-colonizado nas Minas Gerais do século XVIII, o colonizador que se impõe pela força mas também pela aniquilação dos povos nativos. No discurso de Dimas, reverbera o enunciado da ciência confrontado pelo inexplicável, pelo insólito, por aquilo que escapa à razão e ao conhecimento científico.

O jogo constitutivo das temporalidades e o embate entre os cronotopos de um passado que ainda sobrevive por meio de relações de poder e, por que não dizer, de sangue permitem compreender a minissérie como uma metáfora da nação no sentido atribuído por H. Bhabha (2003), ou seja, como formas de compreender os sentimentos e as temporalidades que fazem com que uma determinada coletividade se compreenda como nação. De acordo com H. Bhabha (2003, p. 206), o conceito de povo não se constrói apenas pela reiteração dos "eventos históricos" ou dos "componentes de um corpo político patriótico", mas principalmente por "uma complexa estratégia retórica de referência social".

Trata-se, portanto, de um movimento de constante produção de sentidos por meio de discursos que atualizam fatos históricos, que os ressignificam instaurando novas instâncias enunciativas que constituem novos enunciadoresenunciatários potencializados pela atualização - ou seja, pela instauração do tempo-duplo do qual fala $\mathrm{H}$. Bhabha. É preciso que se encontrem no discurso do passado significados que façam sentido no presente, que digam alguma coisa aos sujeitos do presente. Assim, os discursos de Silvério refletem o espírito que presidiu as ações do colonizador e refratam a materialidade das relaçoes de poder inscritas na sociedade brasileira. 


\section{Considerações finais}

A narrativa fantástica se constitui por meio de uma profunda relação com a realidade, sua força encontra-se na construção de uma trama que, concomitantemente, articula o ordinário (comum, cotidiano) ao extraordinário, ou ainda, o temporal ao intemporal. Isso pois produz sentido ao colocar em jogo as angústias, os medos, as dúvidas que se articulam com o tempo da história, das personagens e com o tempo e os temas da própria dimensão ontológica humana face à filogênese e à sociogênese. Articulam-se o pequeno e o grande tempo (BAKHTIN, 2003) num jogo de simultaneidades e complementaridades, que se manifestam na obra artística por meio do cronotopo (BAKHTIN, 1993).

Dentro desse quadro, $A$ cura apresenta-se como uma narrativa que ganha força justamente por não se enredar pelos caminhos simples da dicotomia entre o bem e o mal, mas pela vigorosa correlação/contraposição que estabelece entre tempos, valores e visões de mundo ancorados na complexa e paradoxal constituição do ser humano como ser social. Assim, o cronotopo do explorador ambicioso e sem escrúpulos do século XVIII se atualiza nas maldades e sede de poder de Otto; ao mesmo tempo, a história também deixa claro que é possível lutar contra o mal e as sutilezas de seu discurso enganador.

O estudo aqui apenas esboçado desvela a centralidade das narrativas de realismo fantástico e de apelo ao sobrenatural na teledramaturgia brasileira. Resultado de longa experimentação, a adoção de temas e de personagens que remetem ao fantástico evidencia características culturais que aproximam a obra artística do público, solicitando deste uma identificação que passa pela hesitação e pela busca de respostas frente ao improvável, embora verossímil. 


\section{Referências}

BHABHA, H. K. O local da cultura. Belo Horizonte: Ed. UFMG, 2003.

BAKHTIN, M. Questões de literatura e de estética: a teoria do romance. São Paulo: Hucitec/Editora da UNESP, 1993.

BAKHTIN, M. Estética da criação verbal. São Paulo: Martins Fontes, 2003.

BAKHTIN, M. Marxismo e filosofia da linguagem. São Paulo: Hucitec, 2002.

DE CERTEAU, M. A invenção do cotidiano. Vol. 1: artes de fazer. Petrópolis: Vozes, 2007.

ECO, U. Seis Passeios pelos bosques da ficção. São Paulo: Cia. das Letras, 1997.

FERNANDES, I. Telenovela brasileira: memória. São Paulo: Brasiliense, 1987.

FORSTER, E. M. Aspectos do romance. São Paulo: Globo, 1998.

LE GOFF, J. História e memória. Campinas, SP: Editora da UNICAMP, 2003.

LOPES, M. I. V. "Para uma revisão das identidades coletivas em tempo de globalização".

In: LOPES, M. I. V. Telenovela: intercionalização e interculturalidade. São Paulo, Loyola, 2004. pp. 121-137.

MEMÓRIA GLOBO. Site. Disponível em: http://memoriaglobo.globo.com/.

MERQUIOR, J. G. "Situação do escritor". In: MORENO, C. F. América Latina em sua literatura. Unesco. São Paulo: Perspectiva, 1979. pp.383-399.

MOTTER, M. L. "Telenovela: documento histórico e lugar de memória". Revista USP, São Paulo, n. 48. dez.-fev. 200-2001.

MUNGIOLI, M. C. P. "Ecos da memória da nação na minissérie Queridos Amigos". Communicare. v. 10, edição 2, 2010. 
PROJETO MEMÓRIA GLOBO. Guia Ilustrado TV Globo: novelas e minisséries. Rio de Janeiro: Jorge Zahar Ed, 2010.

TODOROV, T. Introdução à literatura fantástica. São Paulo: Perspectiva, 2008.

TODOROV, T. As estruturas narrativas. São Paulo: Perspectiva, 2003. 